\title{
24-hour Intraocular Pressure and Ocular Perfusion Pressure in Glaucoma
}

\author{
Luciano Quaranta, MD, PhD, ${ }^{1}$ Andreas Katsanos, MD, PhD, ${ }^{1,2}$ Andrea Russo, MD, ${ }^{1}$ \\ and Ivano Riva, MD
}

${ }^{1}$ Department of Ophthalmology, University of Brescia, Brescia, Italy; and ${ }^{2}$ Department of Ophthalmology, University of Ioannina, Ioannina, Greece

\begin{abstract}
This review analyzes the currently available literature on circadian rhythms of intraocular pressure (IOP), blood pressure, and calculated ocular perfusion pressure (OPP) in patients with openangle glaucoma. Although adequately powered, prospective trials are not available. The existing evidence suggests that high 24-hour IOP and OPP fluctuations can have detrimental effects in eyes with glaucoma. The currently emerging continuous IOP monitoring technologies may soon offer important contributions to the study of IOP rhythms. Once telemetric technologies become validated and widely available for clinical use, they may provide an important tool towards a better understanding of longand short-term IOP fluctuations during a patient's daily routine. Important issues that need to be investigated further include the identification of appropriate surrogate measures of IOP and OPP fluctuation for patients unable to undergo 24-hour measurements, the determination of formulae that best describe the relationship between systemic blood pressure and IOP with OPP, and the exact clinical relevance of IOP and OPP fluctuation in individual patients. Despite the unanswered questions, a significant body of literature suggests that OPP assessment may be clinically relevant in a significant number of glaucoma patients. (Surv Ophthalmol 58:26-41, 2013. (C) 2013 Elsevier Inc. All rights reserved.)
\end{abstract}

Key words. glaucoma • circadian rhythm • intraocular pressure • blood pressure • ocular perfusion pressure

\section{Physiological Considerations}

The principal physiological entities that affect intraocular pressure (IOP) and its characteristics are the aqueous humor $(\mathrm{AH})$ dynamics in healthy and glaucomatous eyes.

The production of AH involves two consecutive processes. First, a portion of the plasma that reaches the vascular plexus of the ciliary processes is filtered through the fenestrated capillaries into the interstitial space between the vessels and the ciliary epithelia. Next, a portion of the filtrate is actively secreted by the ciliary epithelial cells into the posterior chamber.

In humans, these processes are affected by age, circadian rhythm, topical and systemic medications, and the presence of glaucoma. ${ }^{63,64,70,109,121}$ The rate of AH formation decreases with age: by $15-35 \%$ between age 20 and 80 years. ${ }^{15,30}$ The rate of $\mathrm{AH}$ production in humans is significantly lower at night, ${ }^{99,119}$ attributed to decreased endogenous circulating catecholamine levels, which may partly explain the decreased nocturnal efficacy of topical 
beta blockers. ${ }^{5,65,68,80}$ Other medications affecting $\mathrm{AH}$ flow are $\alpha$-agonists and carbonic anhydrase inhibitors. Although the efficacy of $\alpha$-agonists to suppress AH production is limited at night, carbonic anhydrase inhibitors have similar efficacy throughout the 24-hour cycle. ${ }^{68,69,119}$ Larsson et al found that the diurnal rate of $\mathrm{AH}$ formation in untreated open-angle glaucoma (OAG) patients was similar to age-matched controls; ${ }^{55}$ glaucoma patients, however, had a higher rate of $\mathrm{AH}$ formation at night.

\section{A. THE CONVENTIONAL PATHWAY}

The bulk of aqueous humor in human eyes drains through the conventional outflow pathway in a largely pressure-dependent fashion. This pathway comprises the inner uveal and the deeper corneoscleral parts of the trabecular meshwork, the juxtacanalicular connective tissue, the endothelial lining of Schlemm's canal, Schlemm's canal itself, the collecting tubules and aqueous veins, and the episcleral veins. The site of increased resistance in eyes with glaucoma is thought to be located at the juxtacanalicular connective tissue and the endothelial lining of Schlemm's canal as a result of composition changes in extracellular matrix components. ${ }^{14,26,32,33,42,72,74,114}$ Outflow facility in ocular hypertensive ${ }^{120}$ and OAG patients is significantly lower than in age-matched controls. ${ }^{55}$ Recent results indicate that outflow facility is decreased at night in older healthy individuals. ${ }^{63}$ Additionally, studies in healthy and OAG patients have shown that outflow facility decreases with age, ${ }^{7,121}$ although this reduction in outflow is paralleled by an age-related reduction in aqueous formation. ${ }^{15}$

\section{B. THE UVEOSCLERAL (UNCONVENTIONAL) PATHWAY}

A significant proportion of aqueous in humans drains through the uveoscleral or unconventional pathway. This route is often referred to as pressureindependent because, at least within the normal IOP range, the uveoscleral flow does not depend on the level of IOP to the same extent as trabecular outflow. $^{2}$ Based on indirect measurements and estimations, this route constitutes $12-54 \%$ of total outflow in healthy human eyes. ${ }^{2,121}$ There is no conclusive evidence that flow through this pathway is reduced in human eyes with glaucoma. Uveoscleral outflow at night decreases as measured by tonographic outflow facility, ${ }^{63}$ but these findings were not reproduced when fluorophotometric outflow facility was used for the calculations. ${ }^{63}$ Uveoscleral flow decreases with age, ${ }^{121}$ which is attributed to the progressive increase of connective tissue in the aging ciliary muscle. ${ }^{115}$ Several medications exert clinically relevant effects on this pathway. Prostaglandin derivatives induce an early, as well as a delayed, ocular hypotensive effect by increasing uveoscleral outflow. The former effect is thought to result from relaxation of the ciliary muscle, which augments the egress of aqueous through the ciliary body, ${ }^{15}$ whereas the later is attributed to interstitial tissue remodeling. ${ }^{73,124}$ Early reports ${ }^{11}$ and animal experiments ${ }^{10}$ indicated that pilocarpine minimizes uveoscleral flow by increasing the ciliary muscle tone and thus obliterating intramuscular spaces; these observations, however, have not been confirmed in human studies. For example, Toris et al have shown that pilocarpine does not inhibit the increase of uveoscleral outflow induced by latanoprost. ${ }^{122}$ Although the interaction of pilocarpine and prostaglandin derivatives can be complex, ${ }^{45}$ pilocarpine does not seem to adversely affect uveoscleral flow in humans and can be combined with prostaglandins. ${ }^{38}$

A retrospective analysis of data from fluorophotometry studies ${ }^{34}$ described new associations between parameters of aqueous dynamics in healthy eyes and those with ocular hypertension. In both groups, a significant positive correlation was found between aqueous inflow and trabecular meshwork facility, suggesting a possible autoregulatory mechanism. On the other hand, a positive correlation was found between aqueous inflow and uveoscleral outflow in controls, but not ocular hypertensives. Finally, in both groups, thicker corneas were associated with lower aqueous production and lower uveoscleral outflow. Neither the pathophysiologic basis nor the clinical significance of these findings is currently clear.

\section{Circadian Blood Pressure Variation}

Blood pressure (BP) is one of the numerous metabolic systems in humans that exhibit a circadian rhythm (Fig. 1). ${ }^{82,104,113}$ For example, Millar-Craig et $\mathrm{al}^{82}$ have shown that $\mathrm{BP}$ is lowest at around $3 \mathrm{AM}$ and increases gradually during the early morning hours before waking, reaching a peak at midmorning. The $\mathrm{BP}$ rise that begins before waking was not associated with physical activity. These fluctuations have been attributed to the nocturnal decrease of sympathetic activity and circulating catecholamines. Importantly, cardiovascular events such as myocardial ischemia and infarction or stroke follow a circadian pattern that has been associated with cardiovascular parameter changes. ${ }^{84}$

Based on the magnitude of the nocturnal BP reduction, patients are often categorized as nondippers if the nocturnal decline is small or absent 


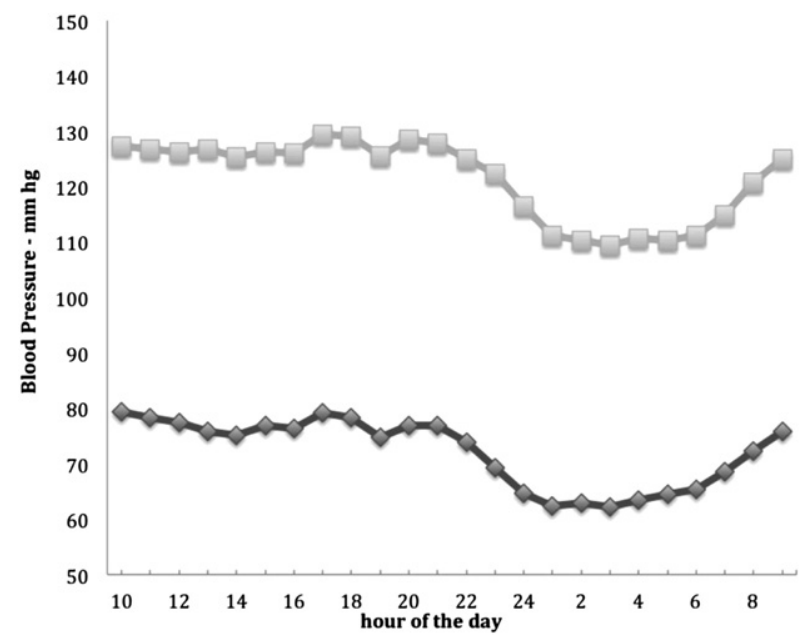

Fig. 1. Circadian mean pattern of systolic and diastolic blood pressure in 34 combined dipper and non-dipper patients. Modified from Staessen et al. ${ }^{107}$

$(<10 \%)$, dippers if their BP falls by $10-20 \%$, and over-dippers if their pressure falls excessively $(>20 \%)$. This classification was adopted following observations that hypertensive patients who did not exhibit a nocturnal BP drop (non-dippers) had a higher risk of vascular damage than the majority of patients with a dipping pattern. ${ }^{27,105,123}$ Compared with dippers, both non-dippers and over-dippers may have a suboptimal mechanism of circadian BP regulation, which is associated with a higher risk of vascular end-organ damage. ${ }^{27,28,123}$ Based on these findings, there is a potential relationship between glaucoma and nocturnal variations in $\mathrm{BP}^{31,36,117}$ Tokanuga et $\mathrm{al}^{117}$ compared dippers with nonphysiologic dippers (non-dippers and over-dippers) and found that non-physiologic dippers had a higher incidence of visual field progression over a 4-year period. Similarly, Graham and Drance ${ }^{31}$ showed that patients with greater nocturnal BP dips were more likely to have shown visual field progression despite seemingly adequate IOP control.

Studies on circadian BP curves are usually performed on inpatients. Twenty-four-hour BP measurements performed in a hospital setting may not accurately reflect a patient's usual circadian rhythm during routine daily life. ${ }^{91}$ Thus, findings from institution-based BP measurements may need to be interpreted with caution.

\section{Circadian Intraocular Pressure Variation}

Existing literature is divided on the importance of IOP variability as an independent factor of glaucoma development and progression. The term "fluctuation" loosely describes variation in IOP during a given day, across days to months, or across years. We use the following terminology:

- Diurnal fluctuation: Daytime IOP variation measured during a particular day or 24-hour cycle.

- Nocturnal fluctuation: Night-time IOP variation measured during a particular 24-hour cycle.

- Circadian fluctuation: IOP variation measured during a particular 24-hour cycle.

- Short-term fluctuation: Inter-visit IOP variation measured across days to months.

- Long-term fluctuation: Inter-visit IOP variation measured across months to years.

Corneal biomechanical properties may influence circadian IOP measurements as evidence exists for their phasic alteration throughout the 24-hour cycle. ${ }^{46}$ The observed circadian variations in parameters such as central corneal thickness or hysteresis, however, do not seem to account for the respective IOP rhythms.

An inherent problem with circadian IOP investigations is the assumption that awakening patients at night for IOP measurements does not significantly affect their endogenous IOP rhythm. To further compound the problem, patients are often asked to walk to a nearby slit-lamp and have their IOP measured in the sitting position. A newly developed 24-hour telemetric contact lens-embedded IOP sensor allows undisturbed tonometry of OAG patients at home ${ }^{78}$ and corroborates some of the existing evidence regarding the circadian IOP pattern found in sleep laboratory studies. ${ }^{64,65,70}$

\section{A. EVIDENCE FOR THE ROLE OF SHORT-TERM IOP VARIATION IN GLAUCOMA}

The rationale for IOP measurements throughout the 24-hour cycle is that IOP exhibits timedependent variation that can reach up to $6 \mathrm{~mm}$ $\mathrm{Hg}$ over a 24-hour period in healthy eyes, even more in eyes with glaucoma. ${ }^{24,25,54,71}$ Therefore, a single office-hour IOP measurement offers little information regarding the IOP profile of a particular patient. This variation may be associated with optic nerve injury because, at least in principle, the continuous and excessive fluctuation of parameters in any biological system may overwhelm the homeostatic mechanisms responsible for buffering stresses and thus cause tissue damage.

Different levels of evidence regarding the role of IOP characteristics in glaucoma can be found in several reports. ${ }^{8,9,23,35,85,88,98}$ Large, well-designed, prospective studies on the importance of circadian IOP fluctuation are currently lacking, and the 
existing literature has not produced consistent results. For example, Asrani et $\mathrm{al}^{3}$ found a strong association between diurnal fluctuations of IOP and progression in 105 eyes of 64 treated OAG patients using self-tonometry. Both the diurnal IOP and the short-term fluctuation over multiple days were significant predictors of progression. The mean office IOP had no predictive value, and the mean home IOP showed a weak association with progression. Others, however, have failed to find similar associations. ${ }^{43}$ Consequently, the importance of 24 hour IOP parameters in glaucoma remains an area of controversy even among glaucoma experts. ${ }^{57}$

\section{B. CIRCADIAN IOP VARIATIONS IN UNTREATED HEALTHY OR GLAUCOMATOUS EYES}

The traditional view is that IOP is generally higher in the morning, but recent research in both healthy and glaucomatous eyes has questioned this. Liu et $\mathrm{al}^{64}$ performed 24-hour IOP measurements with a pneumotonometer every 2 hours in two groups of young healthy volunteers in a sleep laboratory. In the first group of 12 participants, IOP was measured in the seated position during the day and the supine position at night, whereas in the second group of 21 volunteers, IOP was determined in the supine position only. For the first group, IOP measured in the supine position at night was significantly higher than in the seated position. This could be explained, at least in part, by the posture-related increase of IOP usually attributed to the increase of episcleral venous pressure. ${ }^{110}$ There was, however, also a significant nocturnal IOP elevation in the group measured only in the supine position $(20.0 \pm$ 0.4 vs $21.3 \pm 0.7 \mathrm{~mm} \mathrm{Hg}$, respectively; $\mathrm{p}<0.05$ ). This may indicate that a true circadian IOP rhythm, aside from posture-related changes, is responsible for the nocturnal IOP increase in these healthy adults. The same investigators also examined the IOP profile of 16 healthy volunteers who had pneumotonometry measurements performed every 2 hours for 24 hours in both the sitting and supine positions. ${ }^{65}$ The mean IOP was significantly higher during the night both for the sitting and the supine positions. Considering the fact that aqueous production is decreased at night ${ }^{65}$ and that changes in episcleral venous pressure cannot account for the differences in sitting 24-hour IOP values, Liu et al suggest that increased outflow resistance at night, an as yet undescribed phenomenon, may be responsible for the increase of nocturnal IOP. Furthermore, both the sitting and the supine 24-hour IOP curves were synchronous, with no difference in the magnitude of variation. Complementing previous findings ${ }^{67}$ these results indicate that the nocturnal IOP elevation can also be detected in the sitting position in healthy adults. In both reports, the IOP troughs appeared at 9:30 PM, and the peaks at 5:30 AM.

These results on healthy volunteers are in contrast with data from a number of institution-based studies on untreated glaucoma patients. Konstas et al found that although peak IOP in up to $45 \%$ of untreated exfoliation glaucoma and $22.5 \%$ of untreated primary open-angle glaucoma (POAG) patients are outside office hours, ${ }^{52}$ the mean peak IOP in 24-hour curves is generally between $6 \mathrm{AM}$ and $10 \mathrm{AM}^{48,49,51}$ Quaranta et al found similar IOP profiles. ${ }^{92-94}$ These discrepancies in the observed circadian IOP patterns may be explained by differences in equipment (pneumotonometer vs Perkins or Goldmann tonometers) or study samples. Age differences in particular need to be taken into account when comparing IOP curves derived from different studies. Mansouri $\mathrm{et} \mathrm{al}^{79}$ found that older healthy individuals in a sleep laboratory, irrespective of body posture, had a mean cosine-fitted peak IOP at around 10:20 AM, whereas the respective peak for younger healthy individuals was earlier, between 5:30 AM and 6:30 AM depending on body posture. Additionally, sleep lab conditions may create an environment that affects biological rhythms. On the other hand, contrary to hospitalbased investigations, sleep laboratory studies may allow for some adjustment to the patient's usual routine of food intake or activities in the sitting or recumbent positions better simulating normal life.

For the majority of patients, 24-hour IOP phasing is impossible. Therefore, the identification of surrogate measures that may reflect nocturnal IOP profiles is desirable. Mosaed et al, in a retrospective chart review in a sleep laboratory, investigated the relationship between nocturnal and office-hours IOP $^{83}$ They analyzed 24-hour IOP data obtained with pneumotonometry from 33 young healthy participants, 35 older healthy participants, and 35 untreated, older glaucoma patients. Measurements were taken every 2 hours in the sitting and supine positions during the diurnal/wake period (7 AM to $11 \mathrm{PM})$ and in the supine position during the nocturnal/sleep period. The mean supine officehours (9:30 AM to 3:30 PM) IOP had a strong correlation with peak nocturnal IOP in older glaucoma patients $(\mathrm{r}=0.713, \mathrm{p}<0.001)$. The correlation was weaker in older healthy participants and absent in younger healthy participants. Similarly for the sitting position, the mean office-hours IOP had a strong correlation with peak nocturnal IOP in older glaucoma patients, but the correlation was weaker in older healthy participants and absent in 
younger healthy participants. Using linear regression, the authors developed two formulae:

$$
\begin{aligned}
& \text { Peak nocturnal IOP }=12.04+0.616 \\
& \times \text { average office-hour sitting IOP }\left(\mathrm{r}^{2}=0.361\right)
\end{aligned}
$$

Peak nocturnal $\mathrm{IOP}=5.98+0.771$

$$
\times \text { average office-hour supine IOP }\left(\mathrm{r}^{2}=0.508\right)
$$

The investigators suggested that these formulae may assist clinicians predict peak nocturnal IOP values, based on office-hour supine or sitting measurements in a significant proportion of older glaucoma patients.

A recent prospective, multicenter study ${ }^{93}$ also addressed the relationship between daytime sitting IOP as a surrogate to nocturnal supine IOP in untreated POAG patients (Fig. 2). The investigators used Goldmann tonometry around the 24-hour cycle and Perkins tonometry for nocturnal supine measurements. The mean diurnal sitting readings $(23.3 \pm 3.4$ $\mathrm{mm} \mathrm{Hg}$ ) were higher than the mean nocturnal sitting readings $(21.5 \pm 4.0 \mathrm{~mm} \mathrm{Hg}, \mathrm{p}<0.001)$, but similar to nocturnal supine readings $(22.8 \pm 4.4 \mathrm{~mm} \mathrm{Hg}, \mathrm{p}=$ 0.07). The peak daytime Goldmann readings, however, could not consistently predict the peak nighttime sitting or supine IOP, as only $70 \%$ of the participants were within $1.0 \mathrm{~mm} \mathrm{Hg}$ of the highest daytime reading for all nighttime supine and sitting values.

\section{CIRCADIAN IOP VARIATIONS IN TREATED EYES}

Jonas et $\mathrm{al}^{43}$ performed a retrospective chart review of 855 eyes from 458 treated patients with normal tension glaucoma (NTG), POAG, or ocular hypertension. They investigated the potential association of 24-hour IOP parameters with disease

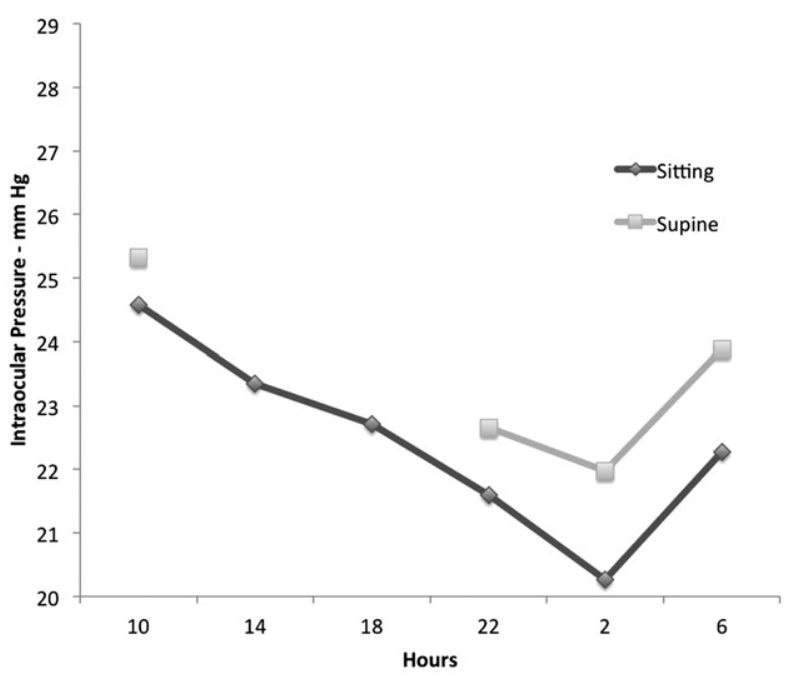

Fig. 2. 24-hour IOP results for sitting and supine position. Adapted from Quaranta et al. ${ }^{93}$ progression after a mean follow-up of almost 56 months. In a multiple Cox proportional hazards analysis, for the whole study population progression was associated with age and neuroretinal rim area. For the POAG group specifically, only age $(\mathrm{p}<$ 0.001 ) was a significant prognostic factor, whereas in the NTG group, higher mean IOP $(p=0.036)$ and lower fluctuation $(p=0.045)$ were identified as predictors of disease progression. Participants were receiving topical medication that is known to reduce IOP levels and its fluctuation, and the effect of 24-hour IOP variation may have been blunted.

In a retrospective chart review of 29 treated POAG and NTG patients, Hughes et $\mathrm{al}^{39}$ found that although the mean office IOP determined in previous visits was similar to the mean 24-hour values, the peak IOP during 24-hour monitoring was almost $5 \mathrm{~mm} \mathrm{Hg}$ higher than the peak office IOP. The mean circadian IOP variation amplitude was $9.4 \mathrm{~mm} \mathrm{Hg}$. More than half of the patients had peak IOP values outside office hours, and in $14 \%$ of them the peak circadian IOP was at least $12 \mathrm{~mm} \mathrm{Hg}$ higher than the office-hour peak. Importantly, circadian IOP measurements led to clinical management modifications in almost $80 \%$ of patients, with $45 \%$ of them being offered trabeculectomy. The high proportion of patients whose management was modified may reflect the fact that these patients were offered a 24-hour monitoring because they were deemed to be progressing despite apparently adequate IOP control. The authors also compared IOP values determined in an outpatient setting using Goldmann tonometry versus values measured during 24-hour phasing using Tono-pen, but argue that the use of Tono-pen in circadian measurements may in fact have underestimated IOP peaks and fluctuation, because data suggest that the Tono-pen may produce lower values than Goldmann at the higher part of the IOP spectrum. ${ }^{4}$

In a similar study, Barkana et $\mathrm{al}^{6}$ reviewed the records of 32 OAG patients who underwent Goldmann tonometry in the sitting position every two hours from 7 AM until midnight and Perkins tonometry in the supine position at 6 AM. They compared office-hours and outside office-hours values recorded on the same 24-hour IOP curve for each patient, as well as IOP values determined in up to five previous outpatient visits. All eyes were treated or had undergone laser trabeculoplasty and/or trabeculectomy. Although the authors report that the mean 24-hour IOP was $13.0 \mathrm{~mm} \mathrm{Hg}$, they do not report the mean office-hour (outpatient or inpatient) IOP. The mean peak 24-hour IOP was higher than the peak office IOP $(16.8 \pm 3.2$ vs $14.7 \pm 3.2 \mathrm{~mm} \mathrm{Hg}, \mathrm{p}<0.001)$ and the mean 24-hour fluctuation was higher than the office-hours 
fluctuation $(6.9 \pm 2.9$ vs $3.8 \pm 2.3 \mathrm{~mm} \mathrm{Hg}, \mathrm{p}<$ $0.001)$. The peak IOP in at least one eye was outside of office hours in almost $70 \%$ of the patients. These findings led them to immediate treatment modification in 19 of 32 patients (59\%), including laser and incisional surgery. Similar to the study by Hughes et $\mathrm{al}^{39}{ }^{39}$ these patients underwent 24-hour phasing because of progression despite apparently good office-hour IOP control. Therefore, the study identified a higher-than-expected proportion of eyes that needed treatment modification.

Nakakura et $\mathrm{al}^{87}$ also investigated the relation between office and 24-hour IOP characteristics in 71 treated eyes of 42 POAG patients. Office IOP was derived from three outpatient measurements (9 AM to $6 \mathrm{PM}$ ) during a six-month period with the same treatment. Circadian measurements were obtained with a Goldmann tonometer in the sitting position at 3-hour intervals. They found no significant difference between mean office and mean 24-hour IOP $(16.2 \pm 4.6$ vs $16.3 \pm 4.9 \mathrm{~mm} \mathrm{Hg}$, respectively), but peak 24-hour IOP was recorded during office hours in only one-third of eyes. Circadian IOP fluctuation (peak minus trough 24-hour IOP) was significantly greater than office-time fluctuation $(6.7 \pm 2.3$ vs $2.7 \pm 1.7 \mathrm{~mm} \mathrm{Hg}$, respectively, $\mathrm{p}<$ $0.001)$, but there was no correlation between them. In these treated patients, only 6 of 71 eyes $(8.5 \%)$ had a circadian curve with fluctuation less than $3 \mathrm{~mm} \mathrm{Hg}$, whereas 10 eyes $(14.1 \%)$ had circadian fluctuation greater than $10 \mathrm{~mm} \mathrm{Hg}$.

The effect of topical glaucoma medication on IOP profile has been the subject of intense investigation and debate. Prostaglandins administered either in the morning or the evening have been shown to have a similar IOP lowering efficacy throughout the 24-hour cycle. ${ }^{108,109}$ Similarly, topical carbonic anhydrase inhibitors seem to have comparable day- and night-time efficacy. ${ }^{92,109}$ Most reports indicate that $\beta$-blockers have a significant, albeit reduced, nighttime efficacy ${ }^{58,92,109}$ that may be explained by the decreased nocturnal aqueous formation. ${ }^{99,119}$ These findings were not confirmed in the sleep laboratory studies by Liu et al, in which topical $\beta$-blockers had a virtually non-existent nocturnal IOP-lowering effect. ${ }^{67,68}$ Finally, brimonidine has been found by most investigators to have a reduced nocturnal efficacy. ${ }^{69,92,109}$

There is limited research on the effects of laser treatment and filtration surgery on circadian IOP rhythm. ${ }^{1,106}$ In a study by Lee et al, ${ }^{56}$ there was no significant reduction in mean, peak, or range of office hour IOP or diurnal IOP after laser trabeculoplasty on 28 treated eyes of 18 glaucoma patients; significant nocturnal IOP reduction was observed, however. Kothy et $\mathrm{al}^{53}$ performed selective laser trabeculoplasty in 26 eyes of 13 patients after appropriate washout and reported that no eyes showed mean circadian IOP reduction of $20 \%$ or more. Nonetheless, the treatment resulted in a significant decrease in the amplitude of circadian IOP fluctuation.

Filtration surgery may provide greater 24 -hour IOP control and smaller IOP fluctuation compared to medical therapy. Medeiros et $\mathrm{al}^{81}$ studied 60 POAG patients considered to be well-controlled who had either undergone one or more trabeculectomies and were untreated $(\mathrm{n}=30)$ or had never had filtering surgery and were receiving a variety of topical medications $(\mathrm{n}=30)$. They evaluated diurnal IOP curves and the response to the water drinking provocation test (WDT) for each group. The WDT was used in the 1950s and 1960s as a diagnostic aid in $\mathrm{OAG}$ and was later advocated as a tool to predict IOP peaks during diurnal phasing, as well as to assess the patency of filtering surgery. ${ }^{17,126}$ The authors found that the diurnal IOP peak was higher and the IOP fluctuation was greater in the medically treated group. The same pattern in IOP peak and fluctuation was seen after the WDT.

In a prospective observational study, Mansouri et $\mathrm{al}^{77}$ examined the diurnal IOP curves of 20 POAG patients considered well controlled (IOP $<18 \mathrm{~mm}$ $\mathrm{Hg}$ ) with latanoprost monotherapy, 20 patients after successful trabeculectomy with mitomycin $\mathrm{C}$ (untreated IOP $<18 \mathrm{~mm} \mathrm{Hg}$ ), and 20 patients after successful deep sclerectomy with collagen implant (untreated IOP $<18 \mathrm{~mm} \mathrm{Hg}$ ). The mean diurnal IOP of the trabeculectomy-treated patients (10.1 $\mathrm{mm} \mathrm{Hg}$ ), was significantly lower than the mean diurnal IOP of the other two groups $(13.7 \mathrm{~mm} \mathrm{Hg}$ and $15.7 \mathrm{~mm} \mathrm{Hg}$ for the deep sclerectomy and the latanoprost-treated groups, respectively; $p=0.1$ for the latanoprost vs deep sclerectomy groups). The diurnal IOP fluctuation was comparable in the three groups. They also examined the patients' IOP changes following the WDT. After the provocation, the latanoprost-treated group had significantly greater IOP elevation compared with the trabeculectomy-treated patients $(p=0.0002)$ and marginally greater elevation compared to the deep sclerectomy group $(\mathrm{p}=0.052)$.

In another prospective observational study, Konstas et $\mathrm{al}^{50}$ compared 30 advanced OAG patients successfully treated with trabeculectomy and 30 patients on maximal medical therapy considered to be adequately treated. They found that the patients with a successful trabeculectomy had lower mean IOP, as well as lower peak and range of IOP over 24 hours, compared with patients on maximal medical therapy. The 24-hour range of IOP was $2.3 \pm 0.8 \mathrm{~mm} \mathrm{Hg}$ for the surgical group and $4.8 \pm 2.3$ 
$\mathrm{mm} \mathrm{Hg}$ for the medical group $(\mathrm{p}<0.0001)$. Most IOP peaks occurred outside of usual office hours.

Despite early recommendations about the clinical usefulness of the WDT, this technique is not performed in most centers because of a number of concerns. First, its sensitivity and specificity may be low when used as a diagnostic tool. ${ }^{97,101}$ Secondly, the test was never standardized, so that the amount and duration of fluid intake or the IOP measurement time points vary widely. Other issues that have not been addressed in relation to the WDT is the possible need for adjustment factors depending on the patient's body weight or prior hydration status. Finally, results of the WDT in medically treated patients may be influenced by when the provocation is performed in relation to the time-dependent hypotensive effects (peak and trough efficacy) of glaucoma medications.

\section{Circadian Ocular Perfusion Pressure Variation}

Lowering of the IOP is the only evidence-based treatment strategy that reduces the risk of development and progression of OAG, but the disease may progress despite adequately controlled IOP, indicating that other factors are often implicated. In particular, the role of vascular dysregulation and the interplay of ocular perfusion pressure (OPP) and blood flow may be important factors in glaucoma. ${ }^{29,37,102}$

Blood flow in any organ is ensured by perfusion pressure, that is, the difference between arterial $\mathrm{BP}$ and venous BP (Fig. 3). Mean arterial blood pressure (MAP) can be calculated as follows:

$$
\mathrm{MAP}=\mathrm{DBP}+1 / 3(\mathrm{SBP}-\mathrm{DBP})
$$

where DBP and SBP are the diastolic and systolic blood pressures, respectively.

In the case of the eye, as IOP can be considered equal to venous pressure, mean ocular perfusion pressure (MOPP) is the difference between ocular MAP and IOP. ${ }^{37}$ As the true MAP at the level of a patient's eye cannot be measured, MAP at the approximate level of the heart from routine brachial artery BP measurement has been used to calculate ocular MAP. Non-human primate experiments have shown that MAP at the level of the eye is approximately two-thirds of the MAP determined at the level of the brachial artery in the upright position. ${ }^{12,75}$ Hence, the following equation is commonly used for the calculation of MOPP from brachial artery MAP values: ${ }^{12}$

$$
\begin{aligned}
\mathrm{MOPP}= & 2 / 3 \mathrm{MAP}-\mathrm{IOP}= \\
& 2 / 3[\mathrm{DBP}+1 / 3(\mathrm{SBP}-\mathrm{DBP})]-\mathrm{IOP}
\end{aligned}
$$

On the other hand, systolic (SOPP) and diastolic (DOPP) ocular perfusion pressures are sometimes calculated without taking into consideration the difference of MAP at the level of the eye and the level of the brachial artery: ${ }^{13}$

$$
\begin{aligned}
& \mathrm{SOPP}=\mathrm{SBP}-\mathrm{IOP} \\
& \mathrm{DOPP}=\mathrm{DBP}-\mathrm{IOP}
\end{aligned}
$$

Some investigators have suggested MOPP be calculated according to the patient's position (sitting or supine), using the following equations: ${ }^{12,67,100}$

$$
\begin{aligned}
& \text { MOPP }(\text { sitting })=(95 / 140 \times \text { MAP })-\text { IOP } \\
& \text { MOPP }(\text { supine })=(115 / 130 \times \text { MAP })-\text { IOP }
\end{aligned}
$$

Regardless of the equations used in these calculations, the resultant values are only a surrogate for the true OPP. Furthermore, there are inevitable measurement inaccuracies during $\mathrm{BP}$ and IOP assessment and the scales differ (IOP values are typically in the $10-30 \mathrm{~mm} \mathrm{Hg}$ range, but $\mathrm{BP}$ values approximate $100 \mathrm{~mm} \mathrm{Hg}$ ). Despite these limitations, several large studies have shown that calculated OPP is a highly relevant parameter in glaucoma.

\section{A. THE IMPORTANCE OF OPP IN OPEN-ANGLE GLAUCOMA PREVALENCE, INCIDENCE, AND PROGRESSION: EVIDENCE FROM LARGE TRIALS}

The Baltimore Eye Survey included an equal proportion of white and black participants and indicated that individuals with DOPP lower than $30 \mathrm{~mm} \mathrm{Hg}$ had a race- and age-adjusted risk of POAG six times higher than individuals with DOPP higher than $50 \mathrm{~mm} \mathrm{Hg} .{ }^{116}$ In participants of Africandescent studied in the Barbados Eye Study, lower DOPP was associated with higher prevalence of OAG. Persons with DOPP values below the 20th percentile were 3.3 times more likely to develop glaucoma. ${ }^{60}$ A subsequent analysis indicated that the 9-year relative risk of incident OAG with low DOPP, low SOPP, and low MOPP was 2.1, 2.0, and 2.6, respectively. ${ }^{62}$ Similarly, the Egna-Neumarkt study found a close relationship between OPP and OAG in white participants: disease prevalence increased at DOPP values less than $70 \mathrm{~mm} \mathrm{Hg}$, although no relationship was detected with either SOPP or MOPP. ${ }^{13}$ In the Proyecto VER study, the prevalence of $\mathrm{OAG}$ in a Hispanic population was found to increase four-fold with lower DOPP, ${ }^{96}$ 


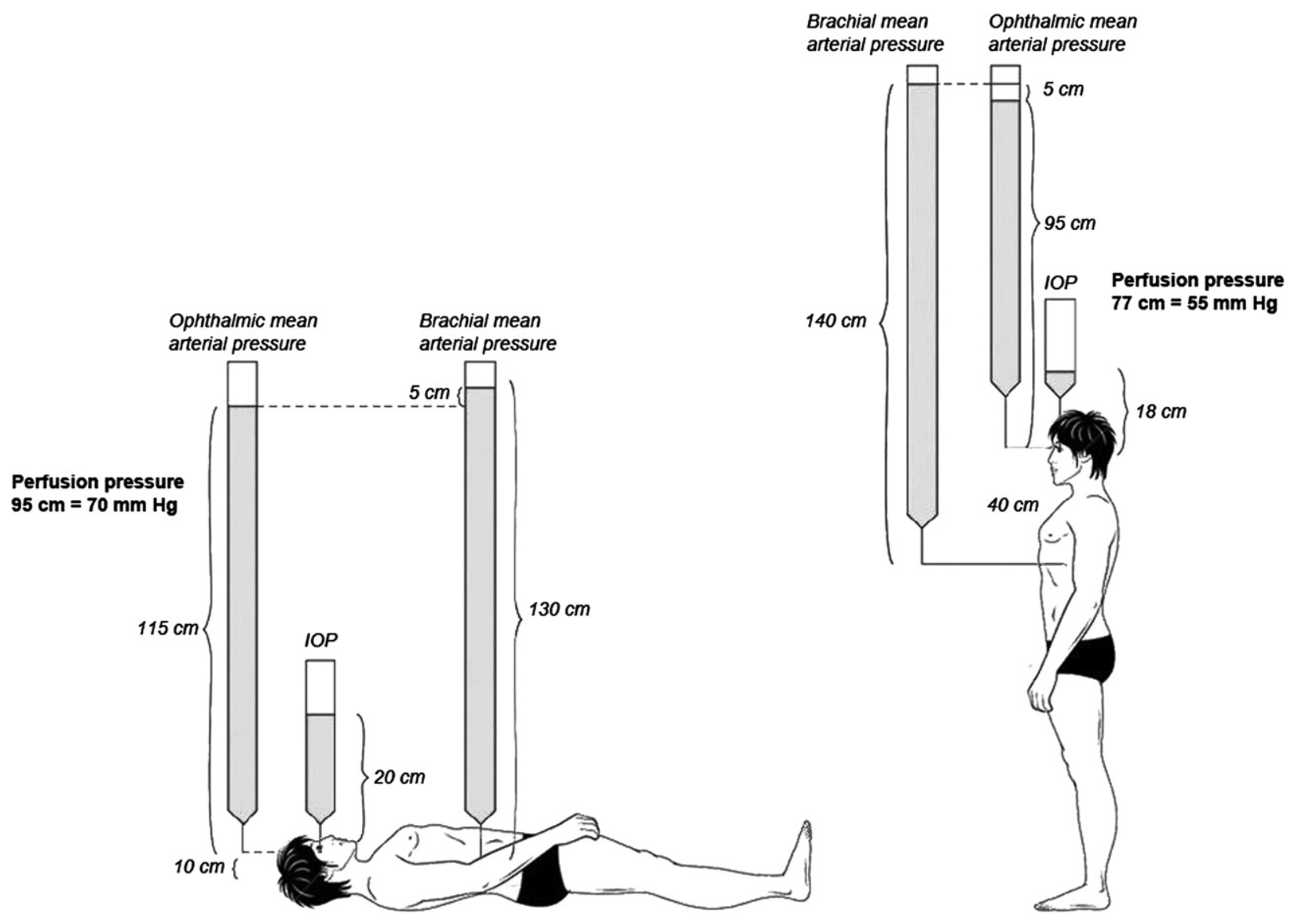

Fig. 3. Hydrostatic column effect of postural position on blood pressure and ocular perfusion pressure. Adapted from Caprioli and Coleman. ${ }^{16}$

whereas in the Rotterdam Study, low DOPP was associated with OAG in white patients with IOP > $21 \mathrm{~mm} \mathrm{Hg}$ who were treated for systemic hypertension. ${ }^{40}$ Data from the Singapore Malay Eye Study showed that $\mathrm{OAG}$ risk is significantly higher in ethnic Malay participants with DBP, MOPP, or DOPP in the lowest quartile than in participants in the highest quartile. ${ }^{127}$ Interestingly, the Beijing Eye Study did not identify OPP as a risk factor for either high- or low-pressure OAG. ${ }^{125}$ Possible reasons for such a discrepancy may result from differences in glaucoma definition, the fact that many patients were untreated, the relatively large proportion of patients with low IOP, and ethnic differences. The Early Manifest Glaucoma Trial (EMGT), a prospective randomized study that evaluated risk factors for progression in 255 white patients with OAG, indicated that low SOPP was a predictor of progression. $^{61}$

Thus, population-based studies and the EMGT show that low perfusion pressure is a risk factor for glaucoma. Nonetheless, these data should be interpreted with caution, because, with the exception of the EMGT, ${ }^{61}$ the Singapore Malay Eye
Study, ${ }^{127}$ and the incidence report of the Barbados Eye Study, ${ }^{62}$ the other results were not adjusted for glaucoma medication or systemic antihypertensive treatment. Furthermore, the significance of low perfusion pressure may be different in persons treated for systemic hypertension. For example, in the Rotterdam Study low DOPP was associated with increased prevalence of glaucoma only in participants treated for hypertension. ${ }^{40}$ Additionally, in the Thessaloniki Eye Study low MOPP was associated with increased cupping and decreased rim area in non-glaucoma patients with decreased diastolic pressure if antihypertensive treatment were used. ${ }^{118}$ Finally, different equations have been used for the calculation of ocular perfusion pressure. The investigators who wrote the incidence report of the Barbados Eye Study ${ }^{62}$ and the Thessaloniki Eye Study ${ }^{118}$ calculated MOPP as (2/3 MAP - IOP). On the contrary, the authors of the EMGT ${ }^{61}$ and the Beijing eye study ${ }^{125}$ calculated MOPP as (MAP IOP).

Because both parameters used in the calculation of OPP (i.e., BP and IOP) exhibit a circadian rhythm, OPP is bound to be affected around the 
24-hour cycle. Recent investigations have examined the characteristics of 24-hour OPP in healthy volunteers and glaucoma patients, and the potential role of such variation in OAG.

\section{B. CIRCADIAN OPP RHYTHM IN HEALTHY EYES}

Liu et al examined diurnal and nocturnal levels of posture-adjusted MOPP in 16 younger and 16 older healthy adults who were not using any systemic anti-hypertensive medication. ${ }^{66}$ In habitual body positions (i.e., sitting at day and supine at night) they found that OPP peaked at night for both younger and older volunteers. Both OPP and the diurnal-to-nocturnal increase of OPP was larger in the older group throughout the 24 hours. Kida et al measured 24-hour OPP and blood flow of the optic disc and macula in 15 younger and 15 older healthy volunteers. ${ }^{47}$ None of the younger participants were using systemic medication, but 12 of the older volunteers were routinely using at least one systemic medication and four of them were on anti-hypertensive drugs. The authors used a scanning laser Doppler flowmeter to record blood volume, flow, and velocity in the sitting position. Older participants had significant decreases in ocular blood flow parameters at night, despite the MOPP (calculated as 95/140 $\times$ MAP - IOP) remaining constant throughout the 24-hour cycle. In younger volunteers, there was no change in ocular blood flow parameters despite the finding that MOPP decreased significantly at night. They concluded that aging may compromise the autoregulatory capacity normally present in healthy younger individuals that ensures adequate ocular blood flow in the face of perfusion pressure reductions. Because all measurements in this study were made in the sitting position, the effects of habitual postural changes were not taken into account.

\section{CIRCADIAN OPP RHYTHM IN EYES WITH GLAUCOMA}

\section{Circadian OPP and Diagnosis or Severity of Glaucoma}

Two studies by Quaranta et al have investigated 24-hour DOPP in newly diagnosed, untreated POAG patients who were not receiving any systemic medication. ${ }^{92,94}$ In both reports, the calculated DOPP peaked in the evening (either $6 \mathrm{PM}$ or $10 \mathrm{PM})$, and the DOPP trough was observed at approximately $4 \mathrm{AM}$. In general, the DOPP curves correlated with the systemic BP curves.

More recently, Costa et $\mathrm{al}^{20}$ examined the circadian IOP, BP, SOPP, and DOPP profiles of 24 healthy adults and 29 washed-out POAG patients with Goldmann tonometry during wake hours (8 AM-10 PM) and Perkins tonometry during sleep hours (12 AM-6 AM). None of the participants were receiving any systemic vasoactive medication. The authors found that both groups tended to have higher IOP values at night. In POAG patients, however, the nighttime IOP increase was accompanied by a simultaneous decrease in DBP, resulting in the reduction of DOPP. Interestingly, glaucoma patients had higher SBP readings than controls at most time-points. As a result, POAG patients had higher (8 AM and 10 AM) or similar SOPP values (12 PM-6 AM) compared with controls.

Sehi et al investigated diurnal OPP profiles of 14 untreated glaucoma patients and 14 age-matched healthy volunteers ${ }^{103}$ who were not receiving any systemic vasoactive medication. They did not specifically indicate if the same applied to the glaucoma patients. Compared to the control group, the glaucoma patients had higher IOP, lower MOPP (calculated as 2/3MAP - IOP), and wider MOPP fluctuations. The minimum MOPP in the glaucoma group was recorded at $7 \mathrm{AM}$, at the time when IOP was at peak and BP at trough. This may suggest that inadequate autoregulatory mechanisms in glaucoma patients could prevent maintenance of adequate blood flow in the face of nighttime changes in IOP and BP.

In a study of 12 NTG patients and 12 controls not using any systemic antihypertensive medication, Okuno et al did not detect significant differences in OPP when measurements were performed at $9 \mathrm{AM}$, $3 \mathrm{PM}$, and $9 \mathrm{PM}^{90}$ As nocturnal OPP was assessed relatively early at $9 \mathrm{PM}$, nighttime changes in $\mathrm{BP}$ and IOP may not have brought about changes in OPP.

In a retrospective analysis that included patients on systemic antihypertensive medication, Choi et al examined sitting IOP and BP over 24 hours in 132 untreated patients with NTG. ${ }^{18}$ Patients were classified into three groups based on the nocturnal MAP reduction from their daytime levels: non-dippers ( $<5 \%$ reduction), dippers (reduction $\geq 5 \%$ but $<10 \%$ ), and over-dippers ( $\geq 10 \%$ reduction). A significant proportion of patients $(41.7 \%)$ were classified as over-dippers. There were no differences among the groups in mean office IOP, IOP fluctuation, mean 24-hour MOPP (calculated as 2/ 3MAP-IOP), and glaucoma severity at diagnosis, but over-dippers had significantly larger MOPP fluctuations than the other groups. In a subsequent report on 113 retrospectively reviewed NTG patients that did not exclude participants on systemic anti-hypertensive medication, Choi et al found that, in a multivariate regression model, larger circadian MOPP fluctuations were significantly associated with 
decreased Humphrey Visual Field Analyzer mean deviation, increased pattern standard deviation, and increased Advanced Glaucoma Intervention Study scores. ${ }^{19}$ Besides the association with functional outcome variables, the model identified MOPP fluctuation as an important predictor of structural damage, such as a thinner retinal nerve fiber layer. They suggested that MOPP fluctuations may be a risk factor for NTG, as reductions of OPP may lead to short-term ocular tissue ischemia, followed by reperfusion injury and consequent loss of retinal ganglion cells.

\section{Circadian OPP and Progression of Glaucoma}

A number of investigations have found an association between increased circadian MOPP fluctuation and glaucoma progression. Sung et al published a retrospective chart review of 101 NTG patients with at least 4 years of follow-up and 24-hour sitting IOP and MOPP tracings. ${ }^{111}$ Multivariate regression analysis identified baseline pattern standard deviation and 24-hour MOPP fluctuations as significant predictors of visual field progression. According to the model, each $\mathrm{mm} \mathrm{Hg}$ increase in MOPP fluctuation was associated with approximately $27 \%$ greater hazard ratio of glaucoma progression during follow-up. The same authors subsequently published another report identifying high diurnal MOPP fluctuation as the most consistent predictive factor for central visual field progression in treated NTG patients. ${ }^{112}$ In their retrospective chart review of 101 eyes, patients with high and low MOPP fluctuation had the same risk of progression in the 10-24 degrees of the visual field. The cumulative probability of visual field progression within the central 10 degrees was significantly higher for patients with higher MOPP fluctuation, however. Multivariate regression analysis found only 24-hour MOPP fluctuation to be a predictor of central visual field progression. In explaining their findings, the authors suggest that the similarity of functional defects often observed in NTG and non-arteritic ischemic optic neuropathy, and the fact that these conditions have been associated with BP decreases, ${ }^{36}$ both point towards disturbances of retrobulbar hemodynamics as important contributing factors.

In a prospective study, Renard et $\mathrm{al}^{100}$ used a nonlinear least-squares dual-harmonic regression analysis to examine 24-hour IOP, BP, and MOPP curves in a group of 27 NTG patients that had been appropriately washed-out of topical medications. They used two different equations for the calculation of MOPP at the sitting and the supine positions:

$$
\begin{aligned}
& \operatorname{MOPP}_{(\text {sitting })}=(95 / 140 \times \mathrm{MAP})-\mathrm{IOP} \\
& \operatorname{MOPP}_{\text {(supine) }}=(115 / 130 \times \mathrm{MAP})-\text { IOP }
\end{aligned}
$$

They found a diurnal IOP peak in 54\% of patients and a nocturnal peak in $36 \%$, and no particular rhythm in $9 \%$. Similarly, 24-hour MOPP was classified as either diurnal $(58 \%$ of cases) or nocturnal (42\% of cases) according to the time of the peak. The MOPP rhythm was closely related to the 24-hour BP curve, rather than the IOP curve. This implies that IOP changes hardly affect OPP changes. As the authors point out, this can be predicted by considering the relative weigh of $\mathrm{BP}$ compared to IOP in the OPP equation. Moreover, the amplitude of MOPP was not significantly associated with glaucoma severity at inclusion.

\section{THE EFFECT OF TOPICAL MEDICATIONS ON OPP RHYTHM}

By influencing IOP and possibly BP profiles, medications used in the management of glaucoma are likely to affect OPP profiles. Ideally, pharmacological agents should lower IOP without adversely affecting OPP. Quaranta et al evaluated the effects of most common anti-glaucoma drugs on 24-hour DOPP $^{92}$ in 27 newly diagnosed, untreated POAG patients given timolol $0.5 \%$ twice daily, brimonidine $0.2 \%$ twice daily, dorzolamide $2 \%$ three times daily, or latanoprost $0.005 \%$ in the evening. Diurnal sitting IOP was measured with a Goldmann tonometer and nocturnal supine IOP with a Tono-pen. Compared with baseline, all medications decreased the IOP significantly at all time points. Details of the 24-hour IOP results of this study were discussed in a previous paragraph. Timolol and brimonidine significantly lowered 24-hour mean BP; timolol caused a fairly uniform, significant decrease in both SBP and DBP at all time points, and brimonidine lowered them mainly during night hours. Compared with baseline, both dorzolamide and latanoprost significantly increased DOPP at all time points. The increase in mean circadian calculated DOPP with timolol was not statistically significant; brimonidine, however, significantly decreased mean 24hour DOPP. In general, both latanoprost and dorzolamide had a statistically similar effect on mean 24-hour DOPP in these naive POAG patients.

In another cross-over study, Quaranta et $\mathrm{al}^{94}$ investigated the effect of latanoprost and timololdorzolamide fixed combination (TDFC) on 24-hour IOP and DOPP in a group of 27 previously untreated, newly diagnosed POAG patients. Both TDFC and latanoprost significantly reduced mean 24-hour IOP, as well as IOP at individual time-points, 
but TDFC had a better treatment effect over the 24-hour cycle $(1.3 \mathrm{~mm} \mathrm{Hg}, \mathrm{p}<0.001)$. Although TDFC lowered both systolic and diastolic 24-hour BP in a statistically significant way, DOPP was significantly increased compared with baseline because of the proportionally greater IOP reduction. Latanoprost did not induce a $\mathrm{BP}$ reduction but its IOPlowering effect resulted in DOPP being increased. The observed elevation of DOPP from baseline was not significantly different for the two medications neither for the 24-hour curve $(5.9 \mathrm{~mm} \mathrm{Hg}$ with TDFC and $6.5 \mathrm{~mm} \mathrm{Hg}$ with latanoprost, $\mathrm{p}=0.09$ ) nor for the night $(5.7 \mathrm{~mm} \mathrm{Hg}$ with either drug, $\mathrm{p}=$ 0.970). The increase from baseline during the day was marginally greater with latanoprost $(6.8 \mathrm{~mm} \mathrm{Hg}$ vs $6.0 \mathrm{~mm} \mathrm{Hg}, \mathrm{p}=0.049)$.

In an open-label study, Ishibashi et $\mathrm{al}^{41}$ investigated the effect of latanoprost $0.005 \%$ on circadian sitting IOP and MOPP (calculated as 2/3MAP IOP) in 22 NTG patients. Latanoprost significantly lowered mean 24-hour IOP, but did not affect BP and MOPP. They suggest that the lack of MOPP change could be attributed to the relatively small IOP reduction $(12.5 \%)$ observed with latanoprost in this series of low-IOP patients $(13.9 \mathrm{~mm} \mathrm{Hg}$ at baseline). Sample size and study design may also account for these results, which were not confirmed by a crossover, investigator-masked study ${ }^{95}$ on the effect of latanoprost $0.005 \%$ and bimatoprost $0.03 \%$ on 24-hour IOP and BP. In 40 newly diagnosed, previously untreated NTG patients, both medications had a similar ocular hypotensive effect over the mean 24-hour IOP (16\% reduction from baseline) and at each time point. Following treatment with latanoprost, the circadian DOPP manifested a small (3\%), but significant, increase compared to baseline $(p=0.031)$. The increase of circadian DOPP was not significant with bimatoprost $(2 \%, \mathrm{p}=0.21)$. When treatments were compared directly, the DOPP was similar in both groups for the 24-hour curve and for all time-points.

In a crossover study of 60 eyes of 30 newly diagnosed NTG patients, Costagliola et $\mathrm{al}^{21}$ investigated the influence of latanoprost $0.005 \%$ and timolol $0.5 \%$ on 24-hour sitting IOP, BP, and MOPP (calculated as 2/3MAP - IOP). Although both medications significantly reduced mean circadian IOP compared to baseline, there was a difference of $1.3 \mathrm{~mm} \mathrm{Hg}$ in favor of latanoprost. Both 24-hour SBP and DBP were significantly reduced after treatment with timolol, but were not changed after treatment with latanoprost. Although latanoprost significantly raised 24-hour MOPP, timolol did not affect it. Compared with the reports previously mentioned, mean IOP at baseline was higher than in other studies with NTG patients $(18.4 \pm 2.3 \mathrm{~mm}$
$\mathrm{Hg}$ ) and single IOP measurements reached $27 \mathrm{~mm}$ $\mathrm{Hg}$, with eight individual readings $\geq 24 \mathrm{~mm} \mathrm{Hg}$.

\section{Conclusion}

The currently available literature on the circadian IOP cycle fails to answer important questions about the optimal way of characterizing IOP fluctuation and the significance of such changes in glaucoma management. Although adequately powered, prospective trials are not available, the data from smaller studies suggest that high 24-hour fluctuation may have detrimental effects in eyes with glaucoma. As 24-hour IOP measurements are impractical for the majority of patients and clinicians, the identification of appropriate surrogate measures of circadian fluctuation is important. The currently emerging continuous IOP monitoring technologies $^{22,44,78}$ may soon offer important contributions to the study of IOP rhythms. Once telemetric technologies become validated and widely available for clinical use, they may provide an invaluable tool towards a better understanding of long- and shortterm IOP fluctuations during a patient's undisturbed daily routine. Some of the obvious benefits for research and clinical purposes include the elucidation of IOP and OPP rhythms in healthy and glaucomatous eyes, the response to medication, or the evaluation of IOP characteristics as predictors of disease progression.

A significant body of literature has highlighted the importance of 24-hour OPP in patients with glaucoma. Nonetheless, the precise relevance of these findings for clinical practice is not always clear. One of the problems with the application of such results to individual patients is related to the fact that the actual validity of calculated OPP measurements is limited. For example, brachial artery pressure is used, with or without correction, instead of ophthalmic or central retinal artery pressure. Additionally, a consensus on the equation that should be used to calculate the OPP in the supine position has yet to be reached. In fact, when the data set of a study by Costa et $\mathrm{al}^{20}$ was analyzed with postured-adjusted OPP formulas, rather than the commonly used single-posture formula, an increase, rather than a decrease, in night-time DOPP was found for POAG patients. ${ }^{76}$ Despite the fact that calculated OPP has proved to be a valuable surrogate of actual OPP, sources of error may still be introduced because the validation of blood perfusion and flow models at the level of the eye is practically unattainable. Additionally, the significance of perfusion pressure across the IOP spectrum may vary. For instance, low DOPP in the Rotterdam Study was associated positively with OAG in patients with IOP $>21 \mathrm{~mm} \mathrm{Hg}$ treated for systemic 
hypertension, but negatively with low-tension OAG patients. ${ }^{40}$ As discussed previously, 24-hour BP measurements (and hence OPP values) performed in a hospital setting may not closely reflect a patient's usual daily rhythm. ${ }^{91}$

Although the relevance of OPP characteristics as risk factors in glaucoma has been highlighted by several studies, an important question that remains is whether increasing the OPP in glaucoma patients would actually be beneficial. Although such a course of action seems biologically plausible, evidence concerning the potential effects of such a strategy is currently lacking. In addition, ophthalmologists need to be aware that although nocturnal hypotension ("dipping") has been associated with glaucoma progression, its existence offers significant protection against cardiovascular mortality. For example, "non-dippers" have a $20 \%$ increased risk of death from stroke, heart attack, or heart failure. ${ }^{27,28,89}$ Based on the notion that low BP can be detrimental for some glaucoma patients, increasing salt intake might appear appealing, but increasing $\mathrm{BP}$ is associated with a higher risk of cardiovascular morbidity. Additionally, caution is needed when systemic medications that have been shown to exert beneficial vasoregulatory effects in experimental settings are used in clinical practice. For example, although systemic calcium channel blockers may enhance ocular blood flow, ${ }^{59}$ there was an increased incidence of glaucoma in patients receiving these medications in the Rotterdam Eye Study. ${ }^{86}$

Despite the recognition of circadian IOP and OPP as important factors in OAG, future research will need to address a number of issues. Because glaucoma represents a heterogeneous group of related optic neuropathies, there may be subgroups of patients in whom vascular factors are important. Consequently, an important direction for future research would be to identify and better characterize these subgroups so that more appropriate treatment strategies are used. Additionally, it will be important to quantify the potential changes in ocular blood flow resulting from changes in OPP. On the other hand, it has been shown that OPP and its circadian rhythm is influenced by the BP and the IOP rhythms. However, the influence of BP on intracranial pressure and its fluctuation, and the potential significance of such changes on the translaminar pressure, remains to be determined. This issue is further complicated by the effects of systemic and topical medication on IOP, BP, and intracranial pressure.

Although more research is needed to refine our current understanding of the role of perfusion pressure and its circadian fluctuation in glaucoma, an appreciable body of evidence indicates that the introduction of OPP evaluation in clinical management may be valuable in a significant number of patients.

\section{Method of Literature Search}

The Medline database was used for the literature search of this review. Although every effort was made to use the most recent references possible, articles irrespective of the year of publication were used if deemed appropriate. The key words searched included: intraocular pressure, ocular perfusion pressure, glaucoma, circadian fluctuation, diurnal rhythm, risk factors. Combinations of these terms with appropriate boolean operators were also used. After retrieving relevant articles using these key words, a search was conducted through the literature cited in these articles and additional papers were identified. Abstracts of papers in languages other than English were surveyed, too. Medical Subject Headings $(\mathrm{MeSH})$ searches were also performed. Case reports and abstracts from meeting presentations were not used.

\section{Disclosure}

The authors report no proprietary or commercial interest in any product mentioned or concept discussed in this article.

\section{References}

1. Agarwal HC, Sihota R, Das C, et al. Role of argon laser trabeculoplasty as primary and secondary therapy in open angle glaucoma in Indian patients. Br J Ophthalmol. 2002; 86:733-6

2. Alm A, Nilsson SFE. Uveoscleral outflow-a review. Exp Eye Res. 2009;88:760-8

3. Asrani S, Zeimer R, Wilensky J, et al. Large diurnal fluctuations in intraocular pressure are an independent risk factor in patients with glaucoma. J Glaucoma. 2000;9: 134-42

4. Bafa M, Lambrinakis I, Dayan M, et al. Clinical comparison of the measurement of the IOP with the ocular blood flow tonometer, the Tono-pen XL and the Goldmann applanation tonometer. Acta Ophthalmol Scand. 2001;79:15-8

5. Bagga H, Liu JHK, Weinreb RN. Intraocular pressure measurements throughout the $24 \mathrm{~h}$. Curr Opin Ophthalmol. 2009;20:79-83

6. Barkana Y, Anis S, Liebmann J, et al. Clinical utility of intraocular pressure monitoring outside of normal office hours in patients with glaucoma. Arch Ophthalmol. 2006; 124:793-7

7. Becker B. The decline in aqueous secretion and outflow facility with age. Am J Ophthalmol. 1958;46(5 Part 1): $731-6$

8. Bengtsson B, Heijl A. Diurnal IOP fluctuation: not an independent risk factor for glaucomatous visual field loss in high-risk ocular hypertension. Graefes Arch Clin Exp Ophthalmol. 2005;243:513-8 
9. Bengtsson B, Leske MC, Hyman L, et al. Fluctuation of intraocular pressure and glaucoma progression in the early manifest glaucoma trial. Ophthalmology. 2007;114: 205-9

10. Bill A, Hellsing K. Production and drainage of aqueous humour in the cynomolgus monkey (Macaca irus). Invest Ophthalmol Vis Sci. 1965;4:920-6

11. Bill A, Phillips CI. Uveoscleral drainage of aqueous humour in human eyes. Exp Eye Res. 1971;12:275-81

12. Bill A. Physiological aspects of the circulation in the optic nerve, in Heilmann K, Richardson KT (eds). Glaucoma: Conceptions of a Disease. Philadelphia, WB Saunders, 1978, pp 97-103

13. Bonomi L, Marchini G, Marraffa M, et al. Vascular risk factors for primary open angle glaucoma: the EgnaNeumarkt Study. Ophthalmology. 2000;107:1287-93

14. Bradley JM, Vranka J, Colvis CM, et al. Effect of matrix metalloproteinases activity on outflow in perfused human organ culture. Invest Ophthalmol Vis Sci. 1998; 39:2649--58

15. Brubaker RF. Flow of aqueous humor in humans [The Friedenwald Lecture]. Invest Ophthalmol Vis Sci. 1991;32: 3145-66

16. Caprioli J, Coleman AL. Blood Flow in Glaucoma Discussion. Blood pressure, perfusion pressure, and glaucoma. Am J Ophthalmol. 2010;149:704-12

17. Chen $\mathrm{CH}, \mathrm{Lu} \mathrm{DW}$, Chang CJ, et al. The application of water drinking test on the evaluation of trabeculectomy patency.J Ocul Pharmacol Ther. 2000;16:37-42

18. Choi J, Jeong J, Cho H-S, Kook MS. Effect of nocturnal blood pressure reduction on circadian fluctuation of mean ocular perfusion pressure: a risk factor for normal tension glaucoma. Invest Ophthalmol Vis Sci. 2011;47:831-6

19. Choi J, Kim KH, Jeong J, et al. Circadian fluctuation of mean ocular perfusion pressure is a consistent risk factor for normal-tension glaucoma. Invest Ophthalmol Vis Sci. 2007;48:104-11

20. Costa VP, Jimenez-Roman J, Carrasco FG, et al. Twenty-fourhour ocular perfusion pressure in primary open-angle glaucoma. Br J Ophthalmol. 2010;94:1291-4

21. Costagliola C, Parmeggiani F, Virgili G, et al. Circadian changes of intraocular pressure and ocular perfusion pressure after timolol or latanoprost in Caucasians with normal-tension glaucoma. Graefes Arch Clin Exp Ophthalmol. 2008;246:389-96

22. De Smedt S, Mermoud A, Schnyder C. 24-hour intraocular pressure fluctuation monitoring using an ocular telemetry sensor: tolerability and functionality in healthy subjects. J Glaucoma. 2012;21 (8):539-44

23. Deokule SP, Doshi A, Vizzeri G, et al. Relationship of the 24-hour pattern of intraocular pressure with optic disc appearance in primary open-angle glaucoma. Ophthalmology. 2009;116:833-9

24. Drance SM. Diurnal variation of intraocular pressure in treated glaucoma. Significance in patients with chronic simple glaucoma. Arch Ophthalmol. 1963;70:302-11

25. Duke-Elder $S$. The phasic variations in the ocular tension in primary glaucoma. Am J Ophthalmol. 1952;35:1-21

26. Ellingsen BA, Grant WM. Trabeculotomy and sinusotomy in enucleated human eyes. Invest Ophthalmol. 1972;11:21-8

27. Fagard RH. Dipping pattern of nocturnal blood pressure in patients with hypertension. Expert Rev Cardiovasc Ther. 2009;7:599-605

28. Ferrara AL, Pasanisi F, Crivaro M, et al. Cardiovascular abnormalities in never-treated hypertensives according to nondipper status. Am J Hypertens. 1998;11(11 Pt 1): 1352-7

29. Flammer J, Orgül S, Costa VP, et al. The impact of ocular blood flow in glaucoma. Prog Retin Eye Res. 2002;21: 359-93

30. Gabelt BT, Kaufman PL. Changes in aqueous humor dynamics with age and glaucoma. Prog Retin Eye Res. 2005;24:612-37
31. Graham SL, Drance SM. Nocturnal hypotension: role in glaucoma progression. Surv Ophthalmol. 1999;43(Suppl 1):S10-6

32. Grant WM. Experimental aqueous perfusion in enucleated human eyes. Arch Ophthalmol. 1963;69:783-801

33. Grant WM. Further studies on facility of flow through the trabecular meshwork. AMA Arch Ophthalmol. 1958;60(4 Part 1):523-33

34. Gulati V, Ghate DA, Camras CB, et al. Correlations between parameters of aqueous humor dynamics and the influence of central corneal thickness. Invest Ophthalmol Vis Sci. 2011;52:920-6

35. Gumus K, Bozkurt B, Sonmez B, et al. Diurnal variation of intraocular pressure and its correlation with retinal nerve fiber analysis in Turkish patients with exfoliation syndrome. Graefes Arch Clin Exp Ophthalmol. 2006;244:170-6

36. Hayreh SS, Podhajsky P, Zimmerman MB. Role of nocturnal arterial hypotension in optic nerve head ischemic disorders. Ophthalmologica. 1999;213:76-96

37. Hayreh SS. Blood flow in the optic nerve head and factors that may influence it. Prog Retin Eye Res. 2001;20:595-624

38. Hoyng PF, Rulo A, Greve E, et al. The additive intraocular pressure-lowering effect of latanoprost in combined therapy with other ocular hypotensive agents. Surv Ophthalmol. 1997;41 (Suppl 2):S93-8

39. Hughes E, Spry P, Diamond J. 24-hour monitoring of intraocular pressure in glaucoma management: a retrospective review. J Glaucoma. 2003;12:232-6

40. Hulsman CAA, Vingerling JR, Hofman A, et al. Blood pressure, arterial stiffness, and open-angle glaucoma: the Rotterdam study. Arch Ophthalmol. 2007;125:805-12

41. Ishibashi S, Hirose N, Tawara A, et al. Effect of latanoprost on the diurnal variations in the intraocular and ocular perfusion pressure in normal tension glaucoma. J Glaucoma. 2006;15:354-7

42. Johnson M. What controls aqueous humour outflow resistance? Exp Eye Res. 2006;82:545-57

43. Jonas JB, Budde WM, Stroux A, et al. Diurnal intraocular pressure profiles and progression of chronic open-angle glaucoma. Eye (Lond). 2007;21:948-51

44. Kakaday T, Hewitt AW, Voelcker NH, et al. Advances in telemetric continuous intraocular pressure assessment. Br J Ophthalmol. 2009;93:992-6

45. Kent AR, Vroman DT, Thomas TJ, et al. Interaction of pilocarpine with latanoprost in patients with glaucoma and ocular hypertension. J Glaucoma. 1999;8:257-62

46. Kida T, Liu JHK, Weinreb RN. Effect of 24-hour corneal biomechanical changes on intraocular pressure measurement. Invest Ophthalmol Vis Sci. 2006;47:4422-6

47. Kida T, Liu JHK, Weinreb RN. Effect of aging on nocturnal blood flow in the optic nerve head and macula in healthy human eyes. J Glaucoma. 2008;17:366-71

48. Konstas AG, Mantziris DA, Cate EA, et al. Effect of timolol on the diurnal intraocular pressure in exfoliation and primary open-angle glaucoma. Arch Ophthalmol. 1997; 115:975-9

49. Konstas AGP, Lake S, Economou AI, et al. 24-hour control with a latanoprost-timolol fixed combination vs timolol alone. Arch Ophthalmol. 2006;124:1553-7

50. Konstas AGP, Topouzis F, Leliopoulou O, et al. 24-hour intraocular pressure control with maximum medical therapy compared with surgery in patients with advanced open-angle glaucoma. Ophthalmology. 2006;113:761-5

51. Konstas AGP, Tsironi S, Vakalis AN, et al. Intraocular pressure control over 24 hours using travoprost and timolol fixed combination administered in the morning or evening in primary open-angle and exfoliative glaucoma. Acta Ophthalmol. 2009;87:71-6

52. Kostas AG, Mantziris DA, Stewart WC. Diurnal intraocular pressure in untreated exfoliation and primary open-angle glaucoma. Arch Ophthalmol. 1997;115:182-5

53. Kóthy $\mathrm{P}$, Tóth M, Holló G. Influence of selective laser trabeculoplasty on 24-hour diurnal intraocular pressure 
fluctuation in primary open-angle glaucoma: a pilot study. Ophthalmic Surg Lasers Imaging. 2010;41:342-7

54. Langley D, Swanljung H. Ocular tension in glaucoma simplex. Br J Ophthalmol. 1951;35:445-58

55. Larsson LI, Rettig ES, Brubaker RF. Aqueous flow in openangle glaucoma. Arch Ophthalmol. 1995;113:283-6

56. Lee AC, Mosaed S, Weinreb RN, et al. Effect of laser trabeculoplasty on nocturnal intraocular pressure in medically treated glaucoma patients. Ophthalmology. 2007; 114:666-70

57. Lee PP, Sultan MB, Grunden JW, et al. Assessing the importance of IOP variables in glaucoma using a modified delphi process. J Glaucoma. 2010;19:281-7

58. Lee PW-Y, Doyle A, Stewart JA, et al. Meta-analysis of timolol on diurnal and nighttime intraocular pressure and blood pressure. Eur J Ophthalmol. 2010;20:1035-41

59. Lesk MR, Wajszilber M, Deschenes MC. The effects of systemic medications on ocular blood flow. Can. J. Ophthalmol. 2008;43:351-5

60. Leske MC, Connell AM, Wu SY, et al. Risk factors for openangle glaucoma. The Barbados Eye Study. Arch Ophthalmol. 1995;113:918-24

61. Leske MC, Heijl A, Hyman L, et al. Predictors of long-term progression in the early manifest glaucoma trial. Ophthalmology. 2007;114:1965-72

62. Leske MC, Wu S-Y, Hennis A, et al. Risk factors for incident open-angle glaucoma: the Barbados Eye Studies. Ophthalmology. 2008;115:85-93

63. Liu H, Fan S, Gulati V, et al. Aqueous humor dynamics during the day and night in healthy mature volunteers. Arch Ophthalmol. 2011;129:269-75

64. Liu JH, Kripke DF, Hoffman RE, et al. Nocturnal elevation of intraocular pressure in young adults. Invest Ophthalmol Vis Sci. 1998;39:2707-12

65. Liu JHK, Bouligny RP, Kripke DF, et al. Nocturnal elevation of intraocular pressure is detectable in the sitting position. Invest Ophthalmol Vis Sci. 2003;44:4439-42

66. Liu JHK, Gokhale PA, Loving RT, et al. Laboratory assessment of diurnal and nocturnal ocular perfusion pressures in humans. J Ocul Pharmacol Ther. 2003;19: 291-7

67. Liu JHK, Kripke DF, Weinreb RN. Comparison of the nocturnal effects of once-daily timolol and latanoprost on intraocular pressure. Am J Ophthalmol. 2004;138: 389-95

68. Liu JHK, Medeiros FA, Slight JR, et al. Comparing diurnal and nocturnal effects of brinzolamide and timolol on intraocular pressure in patients receiving latanoprost monotherapy. Ophthalmology. 2009;116:449-54

69. Liu JHK, Medeiros FA, Slight JR, et al. Diurnal and nocturnal effects of brimonidine monotherapy on intraocular pressure. Ophthalmology. 2010;117:2075-9

70. Liu JHK, Zhang X, Kripke DF, et al. Twenty-four-hour intraocular pressure pattern associated with early glaucomatous changes. Invest Ophthalmol Vis Sci. 2003;44: 1586-90

71. Loewen NA, Liu JHK, Weinreb RN. Increased 24-hour variation of human intraocular pressure with short axial length. Invest Ophthalmol Vis Sci. 2010;51:933-7

72. Lütjen-Drecoll E, Shimizu T, Rohrbach M, et al. Quantitative analysis of "plaque material" in the inner and outer wall of Schlemm's canal in normal and glaucomatous eyes. Exp Eye Res. 1986;42:443-55

73. Lütjen-Drecoll E, Tamm E. Morphological study of the anterior segment of cynomolgus monkey eyes following treatment with prostaglandin F2 alpha. Exp Eye Res. 1988; 47:761-9

74. Mäepea O, Bill A. Pressures in the juxtacanalicular tissue and Schlemm's canal in monkeys. Exp Eye Res. 1992;54: 879-83

75. Mäepea O. Pressures in the anterior ciliary arteries, choroidal veins and choriocapillaris. Exp Eye Res. 1992; 54:731-6
76. Mansouri K, Medeiros FA, Weinreb RN. 24-hour versus daytime intraocular pressure phasing in the management of patients with treated glaucoma [Letter]. Br J Ophthalmol. 2011;95:594-5

77. Mansouri K, Orguel S, Mermoud A, et al. Quality of diurnal intraocular pressure control in primary open-angle patients treated with latanoprost compared with surgically treated glaucoma patients: a prospective trial. $\mathrm{Br} \mathrm{J}$ Ophthalmol. 2008;92:332-6

78. Mansouri K, Shaarawy T. Continuous intraocular pressure monitoring with a wireless ocular telemetry sensor: initial clinical experience in patients with open angle glaucoma. Br J Ophthalmol. 2011;95:627-9

79. Mansouri K, Weinreb RN, Liu JHK. Effects of aging on 24-hour intraocular pressure measurements in sitting and supine body positions. Invest Ophthalmol Vis Sci. 2012;53: $112-6$

80. Maus TL, McLaren JW, Shepard Jw, et al. The effects of sleep on circulating catecholamines and aqueous flow in human subjects. Exp Eye Res. 1996;62:351-8

81. Medeiros FA, Pinheiro A, Moura FC, et al. Intraocular pressure fluctuations in medical versus surgically treated glaucomatous patients. J Ocul Pharmacol Ther. 2002;18: 489-98

82. Millar-Craig MW, Bishop CN, Raftery EB. Circadian variation of blood pressure. Lancet. 1978;1:795-7

83. Mosaed S, Liu JHK, Weinreb RN. Correlation between office and peak nocturnal intraocular pressures in healthy subjects and glaucoma patients. Am J Ophthalmol. 2005; 139:320-4

84. Muller JE, Tofler GH, Stone PH. Circadian variation and triggers of onset of acute cardiovascular disease. Circulation. 1989;79:733-43

85. Musch DC, Gillespie BW, Niziol LM, et al. Intraocular pressure control and long-term visual field loss in the Collaborative Initial Glaucoma Treatment Study. Ophthalmology. 2011;118:1766-73

86. Müskens RPHM, de Voogd S, Wolfs RCW, et al. Systemic antihypertensive medication and incident open-angle glaucoma. Ophthalmology. 2007;114:2221-6

87. Nakakura S, Nomura Y, Ataka S, et al. Relation between office intraocular pressure and 24-hour intraocular pressure in patients with primary open-angle glaucoma treated with a combination of topical antiglaucoma eye drops. J Glaucoma. 2007;16:201-4

88. Nouri-Mahdavi K, Hoffman D, Coleman AL, et al. Predictive factors for glaucomatous visual field progression in the Advanced Glaucoma Intervention Study. Ophthalmology. 2004;111:1627-35

89. Ohkubo T, Hozawa A, Yamaguchi J, et al. Prognostic significance of the nocturnal decline in blood pressure in individuals with and without high 24-h blood pressure: the Ohasama study. J Hypertens. 2002;20:2183-9

90. Okuno T, Sugiyama T, Kojima S, et al. Diurnal variation in microcirculation of ocular fundus and visual field change in normal-tension glaucoma. Eye (Lond). 2004;18:697702

91. Pikilidou MI, Tsirou E, Stergiou GS, et al. Effect of hospitalization on 24-h ambulatory blood pressure of hypertensive patients. Hypertens Res. 2010;33:995-9

92. Quaranta L, Gandolfo F, Turano R, et al. Effects of topical hypotensive drugs on circadian IOP, blood pressure, and calculated diastolic ocular perfusion pressure in patients with glaucoma. Invest Ophthalmol Vis Sci. 2006;47:2917-23

93. Quaranta L, Konstas AGP, Rossetti L, et al. Untreated 24-h intraocular pressures measured with Goldmann applanation tonometry vs nighttime supine pressures with Perkins applanation tonometry. Eye (Lond). 2010;24:1252-8

94. Quaranta L, Miglior S, Floriani I, et al. Effects of the timolol-dorzolamide fixed combination and latanoprost on circadian diastolic ocular perfusion pressure in glaucoma. Invest Ophthalmol Vis Sci. 2008;49:4226-31 
95. Quaranta L, Pizzolante T, Riva I, et al. Twenty-four-hour intraocular pressure and blood pressure levels with bimatoprost versus latanoprost in patients with normaltension glaucoma. Br J Ophthalmol. 2008;92:1227-31

96. Quigley HA, West SK, Rodriguez J, et al. The prevalence of glaucoma in a population-based study of Hispanic subjects: Proyecto VER. Arch Ophthalmol. 2001;119:1819-26

97. Rasmussen KE, Jorgensen HA. Diagnostic value of the water-drinking test in early detection of simple glaucoma. Acta Ophthalmol (Copenh). 1976;54:160-6

98. Realini T, Weinreb N, Wisniewski S. Short-term repeatability of diurnal intraocular pressure patterns in glaucomatous individuals. Ophthalmology. 2011;118:47-51

99. Reiss GR, Lee DA, Topper JE, et al. Aqueous humor flow during sleep. Invest Ophthalmol Vis Sci. 1984;25:776-8

100. Renard E, Palombi K, Gronfier C, et al. Twenty-four hour (Nyctohemeral) rhythm of intraocular pressure and ocular perfusion pressure in normal-tension glaucoma. Invest Ophthalmol Vis Sci. 2010;51:882-9

101. Roth JA. Inadequate diagnostic value of the water-drinking test. Br J Ophthalmol. 1974;58:55-61

102. Schmidl D, Garhofer G, Schmetterer L. The complex interaction between ocular perfusion pressure and ocular blood flow: relevance for glaucoma. Exp Eye Res. 2011;93: 141-55

103. Sehi M, Flanagan JG, Zeng L, et al. Relative change in diurnal mean ocular perfusion pressure: a risk factor for the diagnosis of primary open-angle glaucoma. Invest Ophthalmol Vis Sci. 2005;46:561-7

104. Selmaoui B, Touitou Y. Reproducibility of the circadian rhythms of serum cortisol and melatonin in healthy subjects: a study of three different 24-h cycles over six weeks. Life Sci. 2003;73:3339-49

105. Shimada K, Kawamoto A, Matsubayashi K, et al. Diurnal blood pressure variations and silent cerebrovascular damage in elderly patients with hypertension. J Hypertens. 1992;10:875-8

106. Sit AJ, Asrani S. Effects of medications and surgery on intraocular pressure fluctuation. Surv Ophthalmol. 2008; 53(Suppl 1):S45-55

107. Staessen J, Bulpitt CJ, O'Brien E, et al. The diurnal blood pressure profile. A population study. Am J Hypertens. 1992; 5(6 Pt 1):386-92

108. Stewart WC, Konstas AGP, Kruft B, et al. Meta-analysis of 24$\mathrm{h}$ intraocular pressure fluctuation studies and the efficacy of glaucoma medicines. J Ocul Pharmacol Ther. 2010;26: 175-80

109. Stewart WC, Konstas AGP, Nelson LA, et al. Meta-analysis of 24-hour intraocular pressure studies evaluating the efficacy of glaucoma medicines. Ophthalmology. 2008; 115:1117-22

110. Sultan M, Blondeau P. Episcleral venous pressure in younger and older subjects in the sitting and supine positions. J Glaucoma. 2003;12:370-3

111. Sung KR, Lee S, Park SB, et al. Twenty-four hour ocular perfusion pressure fluctuation and risk of normal-tension glaucoma progression. Invest Ophthalmol Vis Sci. 2009;50: 5266-74
112. Sung KR, Cho JW, Lee S, et al. Characteristics of visual field progression in medically treated normal-tension glaucoma patients with unstable ocular perfusion pressure. Invest Ophthalmol Vis Sci. 2011;52:737-43

113. Takeda N, Maemura K. Circadian clock and vascular disease. Hypertens Res. 2010;33:645-51

114. Tamm ER, Fuchshofer R. What increases outflow resistance in primary open-angle glaucoma? Surv Ophthalmol. 2007; 52(Suppl 2):S101-4

115. Tamm S, Tamm E, Rohen JW. Age-related changes of the human ciliary muscle. A quantitative morphometric study. Mech Ageing Dev. 1992;62:209-21

116. Tielsch JM, Katz J, Sommer A, et al. Hypertension, perfusion pressure, and primary open-angle glaucoma. A populationbased assessment. Arch Ophthalmol. 1995;113:216-21

117. Tokunaga T, Kashiwagi K, Tsumura T, et al. Association between nocturnal blood pressure reduction and progression of visual field defect in patients with primary openangle glaucoma or normal-tension glaucoma. Jpn J Ophthalmol. 2004;48:380-5

118. Topouzis F, Coleman AL, Harris A, et al. Association of blood pressure status with the optic disk structure in nonglaucoma subjects: the Thessaloniki eye study. Am J Ophthalmol. 2006;142:60-7

119. Topper JE, Brubaker RF. Effects of timolol, epinephrine, and acetazolamide on aqueous flow during sleep. Invest Ophthalmol Vis Sci. 1985;26:1315-9

120. Toris CB, Koepsell SA, Yablonski ME, et al. Aqueous humor dynamics in ocular hypertensive patients. J Glaucoma. 2002;11:253-8

121. Toris CB, Yablonski ME, Wang YL, et al. Aqueous humor dynamics in the aging human eye. Am J Ophthalmol. 1999; 127:407-12

122. Toris CB, Zhan GL, Zhao J, et al. Potential mechanism for the additivity of pilocarpine and latanoprost. Am J Ophthalmol. 2001;131:722-8

123. Verdecchia P, Schillaci G, Guerrieri M, et al. Circadian blood pressure changes and left ventricular hypertrophy in essential hypertension. Circulation. 1990;81:528-36

124. Weinreb RN, Kashiwagi K, Kashiwagi F, et al. Prostaglandins increase matrix metalloproteinase release from human ciliary smooth muscle cells. Invest Ophthalmol Vis Sci. 1997;38:2772-80

125. Xu L, Wang YX, Jonas JB. Ocular perfusion pressure and glaucoma: the Beijing Eye Study. Eye (Lond). 2009;23:734-6

126. Yoshikawa K, Inoue T, Inoue Y. Normal tension glaucoma: the value of predictive tests. Acta Ophthalmol (Copenh). 1993;71:463-70

127. Zheng Y, Wong TY, Mitchell P, et al. Distribution of ocular perfusion pressure and its relationship with open-angle glaucoma: the singapore malay eye study. Invest Ophthalmol Vis Sci. 2010;51:3399-404

Reprint address: Prof. Luciano Quaranta, MD, PhD, USVD Centro per lo studio del Glaucoma, Spedali Civili di Brescia, Piazzale Spedali Civili 1, 25123 Brescia, Italy. e-mail: quaranta@ med.unibs.it. 


\section{Outline}

I. Physiological considerations

A. The conventional pathway

B. The uveoscleral (unconventional) pathway

II. Circadian blood pressure variation

III. Circadian intraocular pressure variation

A. Evidence for the role of short-term IOP variation in glaucoma

B. Circadian IOP variations in untreated healthy or glaucomatous eyes

C. Circadian IOP variations in treated eyes

IV. Circadian ocular perfusion pressure variation

A. The importance of OPP in open-angle glaucoma prevalence, incidence, and progression: evidence from large trials
B. Circadian OPP rhythm in healthy eyes

C. Circadian OPP rhythm in eyes with glaucoma

1. Circadian OPP and diagnosis or severity of glaucoma

2. Circadian OPP and progression of glaucoma

D. The effect of topical medications on OPP rhythm

V. Conclusion

VI. Method of literature search

VII. Disclosure 